\title{
COELHO PACHECO: EQUÍVOCOS, COINCIDÊNCIAS E FACTOS
}

COELHO PACHECO: MISTAKES, COINCIDENCES AND FACTS

\author{
Ana Rita Palmeirim*
}

REsumo: Uma breve descrição de como se veio a revelar o verdadeiro autor do poema "Para Além doutro Oceano", destinado a Orpheu 3 e durante muitos anos considerado obra de Fernando Pessoa, seguida de apontamentos biográficos sobre José Coelho Pacheco, o "falso semi-heterónimo de Pessoa". Abordamos também a sua intervenção na revista A Renascença, de 1914, percursora de Orpheu.

Palavras-chave: Coelho Pacheco, Orpheu, Fernando Pessoa, Modernista

ABSTRACT: A brief description of how the true author of "Para Além doutro Oceano" (Beyond Another Ocean), came to light: this poem, intended for Orpheu 3, was for many years considered the work of Fernando Pessoa. Biographical notes on the life on José Coelho Pacheco, "the false semi-heteroym of Pessoa" follow, as well as a look at his participation in the magazine A Renascença, 1914, a predecessor of Orpheu.

KeYwords: Coelho Pacheco, Orpheu, Fernando Pessoa, Modernist

"Investigadora independente e neta de José Coelho Pacheco. Email: anaritapalmeirim@gmail.com 


\section{INTRODUÇÃO}

Como neta de José Coelho Pacheco, o ex-semi-heterónimo de Fernando Pessoa, hoje em dia reconhecido como autor de direito próprio de Orpheu 3, tenho tido o privilégio de pesquisar a sua vida. Vida essa que ele viveu como um verdadeiro Modernista, abraçando todas as novidades do início do século XX, desde a fotografia à aviação, passando, claro está, pela paixão da sua vida, os automóveis.

O longo poema "Para Além doutro Oceano" apareceu a público pela primeira vez numa edição especial da Inquérito, em 1953, com prefácio de Adolfo Casais Monteiro, e com o título: "Poemas inéditos: destinados ao $n^{\circ} 3$ do "Orpheu"' de Fernando Pessoa. Apesar de na página de título do poema constar "Notas de C. Pacheco", o poema é considerado então um "inédito de Fernando Pessoa" e o equívoco instala-se: C. Pacheco passa a ser visto como mais uma personalidade literária de Fernando Pessoa.

No entanto, ao longo dos anos, vários estudiosos puseram em causa este "semi" ou "sub-heterónimo", como chegou a ser chamado. Entre eles António Quadros, amigo da família Pacheco, Pedro da Silveira e a Professora Teresa Rita Lopes. Em 1996, a investigadora Manuela Parreira da Silva encontrou no espólio de Fernando Pessoa uma carta onde, numa folha de papel timbrada da sua firma de automóveis, Coelho Pacheco agradece ao poeta o envio dum exemplar com dedicatória da Mensagem, escrevendo: "Desde o tempo de Orpheu e da «Renascença» (desta talvez já nem se lembre apesar de para ali ter colaborado) sei de cor versos seus d'aquele tempo". Esta descoberta aumentou as dúvidas, mas continuavam a faltar provas concretas da autoria do poema, apesar de Maria Aliete Galhoz ter chegado a escrever, em 2007, um artigo intitulado "O equívoco de Coelho Pacheco".

Quando li o poema "Para Além doutro Oceano" pela primeira vez, por volta de 1983, achei estranho conciliar este semi-heterónimo com a frase da minha mãe ouvida muitas vezes na minha infância e adolescência: "O teu avô foi amigo de Fernando Pessoa." A comprová-lo, o exemplar da Mensagem com dedicatória autógrafa de Pessoa, que a minha tia se orgulha de mostrar.

Há uns anos, obras em casa da filha mais velha de Coelho Pacheco, minha mãe, trouxeram à luz uma pasta de couro com as iniciais J.C.P., cheia de "papeladas velhas", entre as quais os rascunhos manuscritos de "Para Além doutro Oceano". A feliz coincidência de ter reconhecido aqueles versos levou-os às mãos da Professora Teresa Rita Lopes, que, num artigo do JL-Jornal de Letras, Artes e Ideias ( ${ }^{\circ} 1058$, de 20 abril a 3 de maio de 2011) intitulado "O seu a seu dono", reestabeleceu a verdadeira autoria do poema, pondo fim ao equívoco.

José Coelho de Jesus Pacheco, o homem real, nasceu em Lisboa, a 27 de maio de 1894, neto e filho de farmacêuticos. O seu avô, José Bento Coelho de Jesus, um farmacêutico que foi Presidente da Sociedade Farmacêutica Lusitana no início do século XX, foi pai de dez filhos: a mais velha, Maria José, mãe de José Coelho Pacheco; o mais novo, Geraldo Coelho de Jesus, que foi amigo e sócio de Fernando Pessoa. Terá sido provavelmente 
este tio, apenas sete anos mais velho que o sobrinho José, que o apresentou a Pessoa.

José Coelho Pacheco passou a sua infância no coração de Lisboa, habitando a Rua das Portas de Sto. Antão, em frente ao Coliseu, e seguidamente o ${ }^{\circ} 19$ da Av. da Liberdade, bem perto da Praça dos Restauradores. Viveu o Regicídio, a implantação da República e sonhou ser aviador na Grande Guerra.

Filho único, após a morte de uma irmã ainda bebé, José frequenta o Liceu de $\mathrm{S}$. Domingos onde, apesar de ser 3 anos mais novo, foi colega de Mário de Sá-Carneiro. Esteve, com certeza, presente na récita organizada por Sá-Carneiro e o seu grupo de amigos, entre os quais Luís de Montalvor, da peça Hervé de Bazan, cuja receita reverteu a favor das vítimas dum recente incêndio na rua da Madalena. Uma coincidência - uma dessas vítimas, salva por um bombeiro, foi o jovem António Ferro. José segue para o recém-inaugurado Liceu Passos Manuel, onde termina o Liceu em 1911, seguindo para o também novo Instituto Superior Técnico. Apesar da sua paixão pelos motores, nestes anos o seu interesse pela literatura já é óbvio. Prova disso é um pequeno caderno preenchido com poemas, sobretudo sonetos, cuidadosamente passados a limpo e datados de agosto 1910 a janeiro 1913.

Também já traduzia: um esboço de uma co-tradução de uma obra de Júlio Verne tem a data de 1908, tinha José 14 anos, e, em 1912 recebe uma carta de "A Editora Lda." perguntando pelo andamento da tradução de A Aldeia Aérea do mesmo autor. Esta tradução será apenas publicada em 1937, pela casa Bertrand, devido a sucessivas alterações de editoras e não pelo atraso na entrega do trabalho, e ainda hoje é usada em algumas edições eletrónicas.

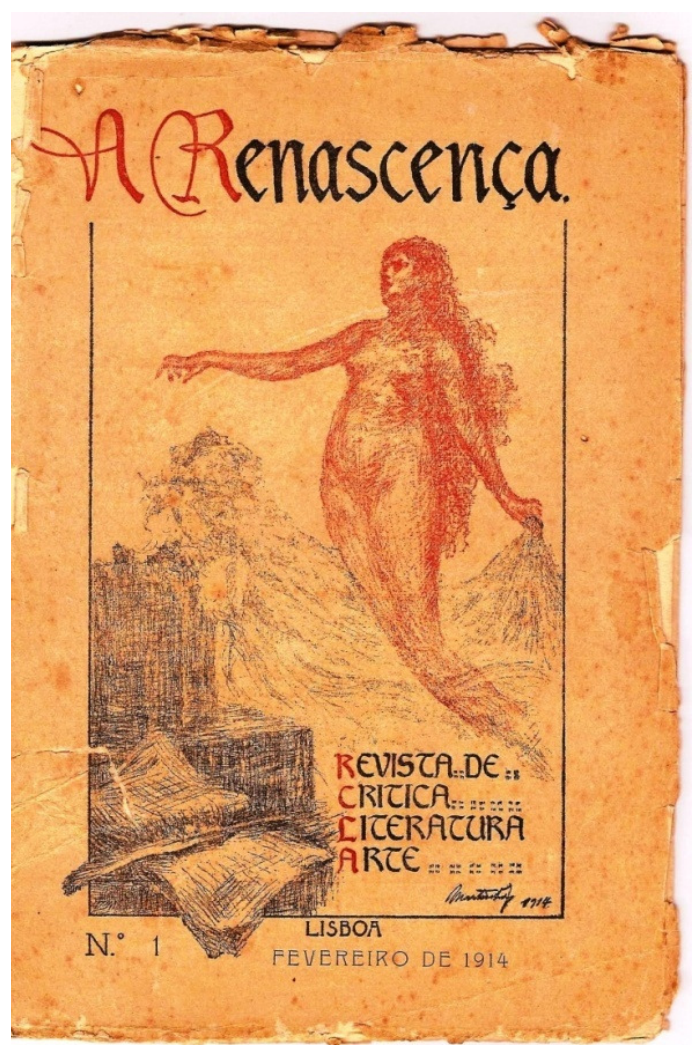

Apesar de inscrito no Instituto Superior Técnico, no curso de Engenharia, o tempo de José parece ter sido dedicado sobretudo à escrita e ao convívio com o grupo de Orpheu. Em 1914, em fevereiro, José Coelho Pacheco surge como Redator e Fernando Carvalho Mourão como Proprietário e Diretor da revista A Renascença, publicando vários futuros autores de Orpheu: Mário de Sá-Carneiro, Alfredo Guisado e Fernando Pessoa. Os dois jovens, na altura com 19 anos, também colaboram como autores. Carvalho Mourão é um poeta que acompanha o percurso de 
José - foram colegas de Liceu, no Instituto Superior Técnico, onde Fernando chega a acabar o Curso, apesar de demorar 10 anos. Nos anos 40 e 50 trabalhará como engenheiro civil.

Em 1908, Carvalho Mourão publica o seu primeiro livro, As Rosas: um Acto em Verso, e, em 1913, publica Pétalas de Rosa, livro de poemas que inclui um intitulado "Sonhos" dedicado "ao meu sincero amigo José Coelho de Jesus Pacheco".Ao longo dos anos, publicará poesia em várias revistas, sobretudo na revista Actualidades, na Ocidente e, mais tarde, na Alma Nova. Fernando Carvalho Mourão escreverá uma das poucas (se não a única) críticas positivas a Orpheu, na revista Terra Nossa de Estremoz. Dedica-se também ao teatro e, em parceria com outros autores, escreverá inúmeras letras para números de revista à portuguesa, ao longo dos anos 20 e 30.

Ao pesquisar a vida de Carvalho Mourão, surgiu uma coincidência: além de terem nascido e falecido com menos de dois meses de diferença um do outro, de terem feito percursos muito semelhantes e habitado quase costas com costas junto à Praça do Saldanha em Lisboa, Fernando e José partilhavam uma prima direita: Maria José Coelho de Jesus Pancada, filha de Sofia Coelho de Jesus e de Manuel Maria Pancada, era a prima preferida de José que, sendo filho único, confraternizava muito com os seus primos. Maria José era prima direita, pelo lado materno, de José, e, pelo lado paterno, de Fernando Carvalho Mourão, cuja mãe era Isabel Maria Pancada. Uma dupla coincidência leva-nos a outro poeta de Orpheu: a casa dos "primos Pancada”, no Largo da Graça, em Lisboa, que
José visitava frequentemente, situava-se no andar por cima da casa de Alfredo Guisado. Ter-se-ão cruzado porventura nas escadas, terão conversado? Terá José frequentado o restaurante da família Guisado, "Os Irmãos Unidos”, onde se reuniam frequentemente os de Orpheu?

Em 1913, Pessoa refere várias vezes encontros com "Coelho" no seu diário. Penso que quando Pessoa escreve apenas Coelho, será a Coelho Pacheco que se refere; quando fala de Ruy Coelho, escreve-o por extenso, e Geraldo Coelho de Jesus é habitualmente Geraldo ou Coelho de Jesus. Coelho será talvez também uma forma de evitar um equívoco e diferenciar José Coelho Pacheco do artista gráfico José Pacheco, que também assinava Pacheko. No diário de Pessoa de 1913, constam duas entradas em que fala do "Coelho" - a 30 Março conversa na Brasileira e depois janta na Imperial com o Coelho, e a 31 escreve: "A meio do dia encontrei o Coelho. Andei de automóvel até às 6 com ele". Terão ido a Sintra? Ao volante de um Chevrolet? Penso que José teria andado de automóvel desde novo. Numa lista encontrada no espólio de Pessoa, com data provável de 1913, Pessoa lista artigos que se propõe escrever: um deles, sobre "automóveis a ar comprimido", tem entre parêntesis o nome (Coelho). De facto, a paixão pelos motores, pela fotografia, por tudo o que era novo, eram bem características de um modernista.

Após vários anos de polémica quanto à autoria do poema "Para Além doutro Oceano", verificamos agora que o nome de Coelho Pacheco consta bastantes vezes no espólio de Fernando Pessoa. Numa lista encabeçada 
Orfeu 3 e 4 estão-lhe reservadas 8 páginas, e surge como autor de um poema Interseccionista intitulado "Eu sem Mim", numa projetada revista Europa, órgão do interseccionismo. "Para Além doutro Oceano” terá provavelmente sido escrito entre 1914 e 15.

Continuando na senda biográfica, em 1915 Coelho Pacheco foi o responsável pela secção dedicada ao Automobilismo nos três números que foram publicados da Illustração Sportiva. Em 1916, após enviar vários textos para apreciação, vê publicado no Correio Literário um soneto e um texto humorístico em prosa.

No entanto, talvez por pressão familiar e apesar de isento do serviço militar, em 1916, pouco tempo após a declaração de guerra da Alemanha a Portugal, José ingressa como voluntário na Escola de Guerra, com o sonho de ser aviador e participar em França na Grande Guerra. Terminado o Curso, é colocado primeiro no Parque Automóvel Militar e, assim que se inaugura o Grupo Esquadrilhas da Aviação República, de alcunha "Os Andorinhas", no campo da aviação da Amadora, José pede transferência. Foi Diretor do Parque de Material e conviveu durante anos, mesmo após a sua saída do G.E.A.R., com os pioneiros da aviação em Portugal.

Em 1919, José viaja para os Estados Unidos com Carlos Mantero, para quem trabalhava na altura como chefe de secção na firma de automóveis «Mantero e Mendonça». Deixou-nos interessantes relatos desta viagem, enviados para a sua noiva Berta Fernandes Leitão, que o aguardava ansiosa por casar antes de fazer 30 anos.
De regresso a Lisboa, casa a 4 de Setembro, véspera do aniversário de Berta, e parte em lua-de-mel para Paris, de onde regressa "ao volante de um Chevrolet", trazendo a sua noiva pelas estradas de França, Espanha e Portugal, num novembro de pós guerra... Chegou a 11 novembro, tendo sido alvo duma campanha publicitária que incluiu um anúncio no Diário de Notícias, convidando a população de Lisboa a ser cinematografada ao assistir à chegada de dois Chevrolets aos Restauradores.

Em 1921, integra os Serviços Gráficos do Exército, Secção de Fotografia e Cinematografia. Talvez pressionado por estar prestes a ser pai, abandona a Aviação, mas regressa ao seu interesse pela fotografia, que aliás nunca abandonou. Já em 1914 José tirava e revelava os seus próprios clichés, assinando e datando alguns dos negativos. Reunimos um espólio de quase cem negativos em vidro que estão neste momento em depósito para eventual recuperação e digitalização no Museu da Imagem e Movimento de Leiria. Pelo que disseram os especialistas, mesmo como amador, José Coelho Pacheco era um fotógrafo de qualidade, que se empenhava em cada imagem que captava.

Em 1924, José estava nos Serviços Gráficos aquando do lançamento do $2^{\circ}$ número de A Revista, composto e impresso pelos Serviços Gráficos do Exército. Esta revista teve um número anterior que ainda não consegui localizar, exceto num catálogo de alfarrabista. O $1^{\circ}$ número tem data de $1924 \mathrm{e}$ é descrito como "tendo reproduções de conceituados mestres portugueses e fotografias retratando os aviadores 
do raid Lisboa-Macau (...)" por coincidência, ou não, os mesmos com que Coelho Pacheco confraternizou nessa época. Terá o então Tenente Coelho Pacheco, que conviveu com António Ferro e Eduardo Malta, tido alguma influência na impressão do $2^{\circ}$ número?

Em 1919, quando se casa, José aluga o r/c esquerdo de um belo edifício apalaçado, um dos últimos que ainda resiste na Praça do Saldanha, em Lisboa, que habitará até 1947. As suas duas filhas nascem em 1921 e 22 e, em 1928, abre o seu stand de automóveis na Rua Braamcamp, onde trabalhará até ao fim da sua vida, em 1951. Dedica ainda muito do seu tempo à Quinta de Sta. Theresa, em S. Pedro de Sintra, que compra em 1938 e onde, em 1943, recebe o ator Leslie Howard. Falece em novembro de 1951, dois anos antes do poema "Para Além doutro Oceano" ser publicado.

Voltemos a 1914 e à Renascença: Diretor e Proprietário, Fernando Carvalho Mourão; Redator, Coelho Pacheco, e Editor e Administrador, Aníbal Tavares. Os dois primeiros com 19 anos, o terceiro com 20 . O texto com que a revista se apresenta tem frases que refletem bem as ideias modernistas dos jovens que a dirigem:

Eis-me, A RENASCENÇA! Leitor amigo, ouve-me! Estou vendo em ti o olhar desconfiado, céptico, com que me lês, desiludido por já tantas minhas companheiras que, abusando da tua boa fé, apenas conseguiram que as olhasses com desdém, deixando-as, aborrecendo-as, odiando-as!

Pobre delas! (...)

Se porém sentires todo o meu sonho, procurarei voar, voar, aventurando-me no éter confuso e indeciso onde tantos limites se buscam e se não atingem, e se no meu caminho vago, idealista, encontrar qualquer novo fulgor divino, subtil, vaporoso, que tu possas sentir tão bem como eu, trar-te-ei dentro em minha alma para te poder deslumbrar com o encantamento leve, apaixonante do seu verbo, que tanta vida nos dará, porque a ambos nos alimenta!

Eis o meu compromisso. Eis o meu intento.

Aníbal Tavares será mais tarde um conhecido ourives e joalheiro, com a sua "Ourivesaria Tavares" a ter um artigo de destaque na Illustração Portuguesa em 1922. Mas, em janeiro de 1914, uma pequena notícia na revista Actualidades fala do "consórcio dos exmos. srs. Irene Costa Tavares e Aníbal Tavares (...) antigo e inteligente empregado da joalharia Mourão “. Já em 1918, no Anuário Comercial de Lisboa, Fernando Carvalho Mourão e Aníbal Tavares constam como sócios da firma de ourivesaria "Mourão e Tavares" e, nesse mesmo ano, Aníbal Tavares é testemunha no casamento de Carvalho Mourão. Parece-me que Aníbal Tavares, o "antigo e inteligente empregado" da Casa Mourão, terá sido chamado a "administrar" o investimento que a família Mourão poderá ter feito n' A Renascença. 


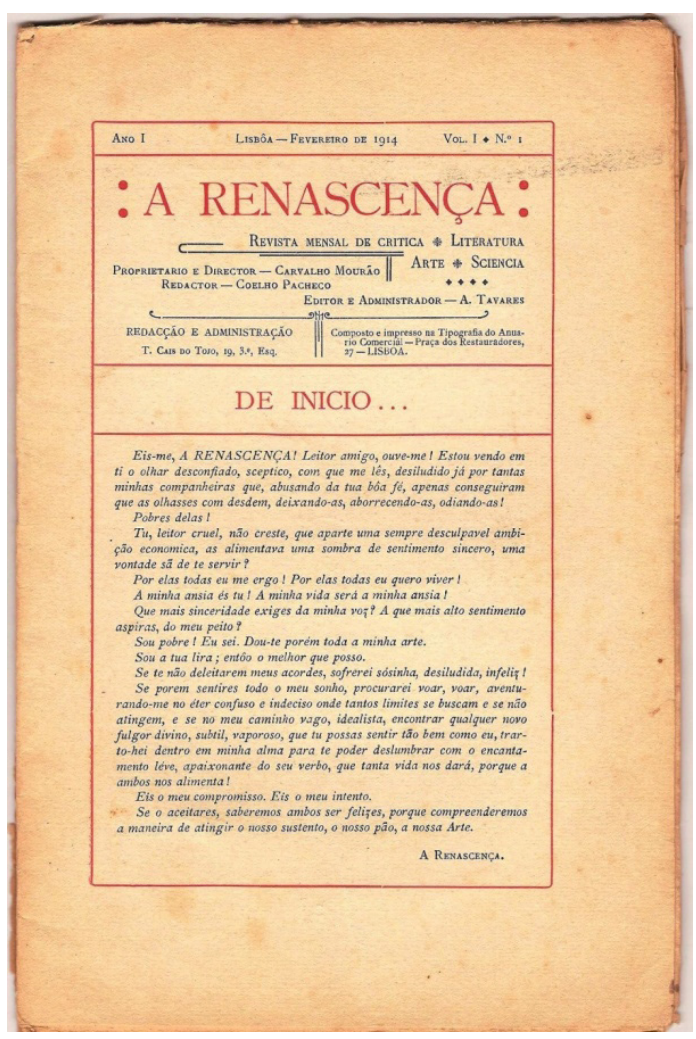

José e Fernando devem ter dedicado muito tempo a esta revista, que no cabeçalho indica Ano $1, n^{\circ}$. Vinha para ficar. Nela, Carvalho Mourão, que já tinha publicado dois livros, em 1908 e 1913, dedica o texto "Visão Cega" a Mário de Sá-Carneiro.

Coelho Pacheco assina um texto humorístico em prosa "O Jornal Dele", "pela cópia Coelho Pacheco". Existem pelo menos duas versões na sua pasta, e numa a indicação "pg. 14" corresponde, de facto, à página onde o texto será publicado n'A Renascença. Também os rascunhos existentes na pasta de Coelho Pacheco vieram esclarecer que a prosa "Zizi", na revista assinada Line, também é da sua autoria.

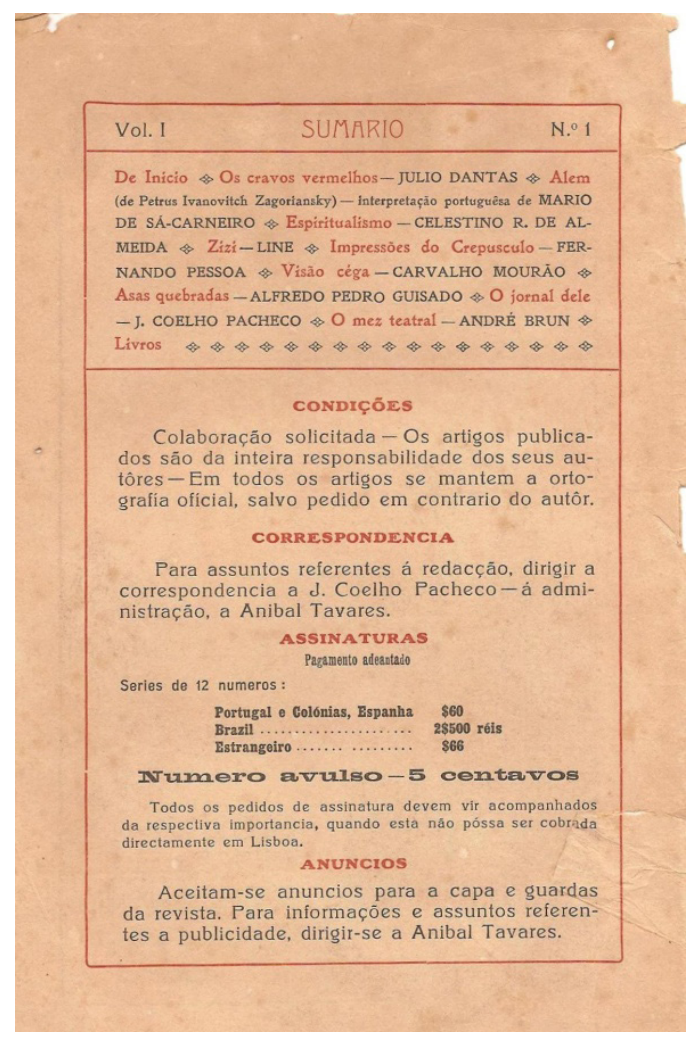

"Zizi" é um texto quase melodramático, oposto à prosa humorística de "O Diário d'Ele". Fala de como um vizinho, "melancólico e triste no recolhimento desesperado da minha tortura de viver", trava amizade com um casal de apaixonados e a sua filha Zizi que vivem no andar de cima. Esta amizade, sempre pura, não aguenta a morte da pequena Zizi, aos 4 anos, e escreve o narrador, o «tio Li»:

Egoísta na própria diluição da dor, egoísta até na partilha das lágrimas devidas a uma alma em flor que se evola da luz ridente desta vida sorvida pelas trevas angustiadas do Além, fugi, isolei-me bem longe de tudo e de todos nesta solidão ignota em que vivo, apartado da vida e da consciência. 
Entre os textos em prosa de Coelho Pacheco que temos, este parece ser o único deste género, sendo a maior parte humorísticos. O pseudónimo "Line" foi de novo usado quando enviou textos para publicação para o Correio Literário, tendo obtido do jornal a seguinte resposta, publicada no $\mathrm{n}^{\circ} 3$ de fevereiro de 1916:

Pede-nos V.Exa. que lhe digamos qual das suas quatro poesias achamos melhor; prontamente: todas quatro. / Pede-nos V.Exa. que lhe digamos qual o género de prosa mais nos apraz que dedique ao Correio Literário; prontamente também: a prosa género "Mangas d'Alpaca" onde V.Exa. se mostra émulo de Fialho e de Eça. (...) O que não é possível é publicarmos as suas poesias com o pseudónimo que trouxeram, porque Line precisa assinar com o seu nome (...) os seus trabalhos.

De referir que nas "Consultas" do número anterior, o $\mathrm{n}^{\circ} 2$ de janeiro de 1916, aparecem duas respostas a J.C.P., numa dizendo que "só se aprecia um trabalho de cada vez, V.Exa. mandou-nos seis!”. Este jornal publicará dois textos de Coelho Pacheco: no ${ }^{\circ} 4$ um soneto, "A Natureza”, e, no $n^{\circ} 6$, a prosa humorística "Mangas-de-alpaca”.

Apesar de não sabermos de mais textos publicados, em 1938, José envia um conjunto de quadras populares à apreciação da escritora e crítica literária Ilda Correia Leite e escreve: "A minha idade e o meu mercantilismo impõem-me um certo decoro". A escritora responde, corrige e dá sugestões e José trabalha ainda mais as suas quadras e volta a enviá-las. As suas quadras são cheias de humor e José dedicou-lhes muito tempo, como comprovam os inúmeros rascunhos e versões nos seus papéis.

Estas tentativas de publicação, assim como a quantidade de rascunhos e manuscritos encontrados, mostram que o seu poema em Orpheu 3 não foi um mero acidente de percurso, mas que José Coelho Pacheco teve uma verdadeira paixão pela escrita. Se pensarmos ainda nas suas paixões por tudo o que era novo, pela fotografia, pelos aviões e, sobretudo pelos automóveis, podemos concluir que a sua vida teve um percurso verdadeiramente Modernista.

Para terminar, dando a palavra a Coelho Pacheco, eis alguns versos não publicados de "Para Além doutro Oceano":

Sinto-me muito feliz quando traço num papel Rabiscos ilegíveis que ninguém perceba Eu nunca procurei saber se eu os entendo Nem preciso de o saber porque me basta E sinto-me feliz dos outros os não saberem ler. Quando escrevo com letras, com estas letras, Lembra-me sempre um obreiro de génio Que tivesse de ir construir nas oficinas alheias As suas máquinas feitas para destinos desconhecidos

E deste modo sinto muitas vezes que me faltam maneiras de dizer ou expressões

Como a ele lhe poderiam faltar as melhores ferramentas

Às vezes tenho ideias tão pequenas que as não compreendo

E uso fugir-lhes. Como se pode supor que uma ideia seja estranha

Se as ideias só podem variar no tamanho Há uma coisa só que eu queria saber como é E de que o ignorá-la me faz oscilar Ela é esta ignorância em que sou 
Do modo como há ligação entre o pensar eu as só minhas ideias

E o aparecerem elas escritas como se fossem de outra pessoa

Recebido para publicação em 18 nov. 2016.

Aceito para publicação em 5 jan 2017. 